\title{
A CARTA DA POPULAÇÃO DE PORTUGAL (1929): UM CONTRIBUTO PARA A HISTÓRIA DA CARTOGRAFIA TEMÁTICA EM PORTUGAL
}

\author{
Mário G. Fernandes \\ FLUP, Departamento de Geografia, CEGOT \\ mgfernandes@letras.up.pt \\ Helder Marques \\ FLUP, Departamento de Geografia, CEGOT \\ htrigo@letras.up.pt \\ Nuno Oliveira \\ Parque Biológico de V. N. de Gaia \\ nuno@parquebiológico.pt
}

\begin{abstract}
Resumo
O património cartográfico de um país percorre caminhos inusitados e, por vezes, os documentos surgem onde não os esperávamos, acrescentando-nos ensinamentos insuspeitados. A Carta da População de Portugal, de 1929 e do Eng ${ }^{\circ}$ Constantino Cabral, existente no Parque Biológico de Vila Nova de Gaia, apresentada e analisada aqui, foi construída a partir de folhas da Carta Corographica do Reino, na escala 1:100.000, e constitui um importante contributo para a história da Cartografia Temática em Portugal, integrável nas representações de implantação pontual de valores absolutos da população do país, que começaram a surgir nesta época com a responsabilidade de geógrafos académicos.
\end{abstract}

Palavras-chave: Cartografia Temática; Círculos proporcionais; População

\begin{abstract}
The heritage cartographic of a country runs unusual ways and, sometimes, the documents emerge were we not expecting them and adding us unsuspected teachings. The Carta da População de Portugal, 1929 and of the engineer Constantino Cabral, existing at the Parque Biológico de Vila Nova de Gaia (Biological Park of Vila Nova de Gaia), presented and analyzed here, was constructed from sheets of Carta Corographica do Reino, with scale 1:100.000, and is an important contribution to the history of Thematic Cartography in Portugal, being integrated in the representations of absolute values of the population of country, which began to emerge at this time to responsibility of academic geographers.
\end{abstract}

Keywords: Thematic Cartography; proportional circles; Population

A Carta da População de Portugal, de 1929, do Eng ${ }^{\circ}$ Constantino Cabral, surgiu num contexto de proliferação de cartografia temática sobre os mais variados assuntos, potenciada pela importante cartografia de base publicada a partir de meados do século XIX, entre a qual se destaca a Carta Geographica de Portugal, na escala 1:500.000, publicada em 1865 pelo Instituto Geographico e a publicação das 37 folhas da Carta Corographica do Reino, na escala 1:100.000, iniciada por Filipe Folque em 1856 e concluída em 1904, muito depois da sua morte.

Naturalmente, porque foi a primeira carta moderna, publicada, a apresentar a totalidade de Portugal Continental e porque permitia a representação de assuntos abrangentes e de alguma generalização, são em grande número os exemplares de cartografia temática conhecidos que assentam na Carta Geographica de Portugal, sendo menos frequentes os exemplos construídos, na escala 1:100.000, a partir de folhas da Carta Corographica do Reino e raríssimos os que utilizam a totalidade constituída pelas 37 folhas, como é o caso do documento objeto da presente análise.

Ora, neste contexto, a Carta da População de Portugal, de 1929, sendo mais um exemplo é também um exemplar notável com características suficientes para constituir uma referência na história da cartografia temática em Portugal. De facto, além de ser um dos raros exemplos de cartografia temática que utiliza como base a totalidade 
das folhas da primeira série cartográfica portuguesa, vem, pelo assunto tratado e pela forma de representação, contribuir para enriquecer dois aspetos daquela história: a representação da população e a utilização dos círculos proporcionais. Na representação da população, porque é enquadrável entre os documentos que, durante 0 segundo quartel do século XX, "vulgarizaram as representações pontuais de valores absolutos da população" (DIAS, H., 1990, p. 57), fazendo-o ao nível da freguesia. No tipo de representação, porque contraria a técnica utilizada, anteriormente e noutros temas, para o cálculo da proporcionalidade dos círculos, aplicando-a em relação à superfície do círculo e não ao comprimento do raio, assim melhorando a exatidão geométrica.

Mas vamos aos documentos, pois, verdadeiramente, devem referir-se dois documentos: a original Carta da População de Portugal, de 1929 e existente no Parque Biológico de Vila Nova de Gaia, e a Carta Demográfica de Portugal, de 1930 e arquivada na Biblioteca da Universidade de Aveiro.

"Carta da População de Portugal, Escala da Carta: 1/100.000, 37 folhas, Escala dos círculos de população (Censo de 1920): 1 milímetro quadrado por cada 10 habitantes." Eng ${ }^{\circ}$ Constantino Cabral, 1929; dimensões de cada folha: $61 \times 88 \mathrm{~cm}$ - Parque Biológico de Vila Nova de Gaia.

"Carta Demográfica de Portugal com as populações por freguesia (censo de 1920) em 37 mapas (S.I.). Companhia Portuguesa para a Construção e Exploração dos Caminhos de Ferro, Escala dos Mapas 1:250.000, Escala dos Círculos de População = 1 mm2 por 62 1/2 Habitantes, Junho de 1930". - "Tiragem limitada a 20 exemplares numerados, reproduzidos das cartas originais a 1/100.000 existentes no arquivo da Administração dos Caminhos de Ferro do Vale do Vouga, que vão rubricados pelo autor. Constantino Cabral, eng ${ }^{0}$ A.P.P. [Academia Politécnica do Porto]."; dimensões do livro: 26×39 cm (mancha cartográfica: 23,5x34 cm) - Biblioteca da Universidade de Aveiro.

Na busca inicial, efetuada na web, a partir do conhecimento da Carta da População de Portugal (1929) encontramos o segundo documento, a Carta Demográfica de Portugal (1930), cuja observação direta, na Biblioteca da Universidade de Aveiro, permitiu concluir tratar-se de uma simples reprodução do primeiro documento, pelo processo de heliocópia e em formato reduzido (figuras 1 e 2), pelo que, não apresentando qualquer alteração de conteúdo e aparentando ter como único objetivo a possibilidade de alguma divulgação (restringida a 20 exemplares), centraremos a presente análise apenas na Carta da População de Portugal.

A Carta da População de Portugal é constituída pelas 37 folhas impressas da Carta Corographica do Reino, tendo cada folha sido retalhada em oito retângulos, devidamente colados em tecido de forma a tronar-se dobrável, à semelhança das cartas de campo (figura 3). Basicamente, o desenhador/executor trabalhou, sobre as folhas adquiridas no Instituto Geográfico e Cadastral (identificado em cada folha com carimbo/selo branco, onde também se refere a Direcção dos Serviços Técnicos e Topográficos e a Divisão de Publicação de Cartas), em dois momentos cronológicos e em dois tempos metodológicos. Cronologicamente, tendo em conta as datas subscritas pelo Eng ${ }^{\circ}$ Constantino Cabral e inscritas no canto inferior direito de cada folha, os momentos de execução foram Agosto e Dezembro de 1929 (em Agosto, as folhas no 7, 8,10, 11, 13, 14, 16, 17, 20 e 21; em Dezembro as restantes folhas - figura 4); metodologicamente, em primeira fase foram introduzidos ajustamentos à informação de base original das folhas da Carta Corographica do Reino, acrescentando-se, em segunda fase, a informação temática relativa à população residente do Censo de 1920.

Os ajustamentos da informação de base prenderam-se com a intenção de salientar três elementos considerados fundamentais pelo autor: os topónimos relativos às sedes de concelho e às freguesias, os primeiros literalmente sublinhados por um segmento de reta sob o respetivo topónimo e em ambos os casos pelo acentuar do preto e do contraste das letras em relação ao fundo de mapa; a rede hidrográfica principal e principais afluentes, com os traçados fluviais a serem aguados de azul, cor também utilizada para salientar as águas do contorno costeiro, de onde resultou algum ruído prejudicial para a leitura cartográfica; finalmente, a rede ferroviária foi relevada através do avivar das linhas pretas correspondentes, mais grossas para a "via larga" e mais finas para a "via estreita".

Para a representação da informação temática, relativa à população residente do Censo de 1920, a opção recaiu na técnica dos círculos proporcionais. Desenhados com a cor vermelha, o que contrasta adequadamente com 0 fundo do mapa, os círculos foram inscritos sobre ou na proximidade dos topónimos das freguesias, na maioria dos casos sem a destrinça da circunferência, a qual apenas é demarcada, pela diferença da saturação da cor (a circunferência mais intensa e o círculo mais transparente), nos concelhos com valores populacionais elevados e 
com muitas freguesias pequenas o que implica a agregação dos valores das freguesias centrais, como acontece nos casos de Lisboa, Porto, Braga, Coimbra e Guimarães (num ou outro caso, apesar da agregação dos valores de população num mesmo círculo não foi utilizada aquela diferenciação visual, como no caso de Viana do Castelo, onde foram adicionados os valores de Monserrate e de Sta Maria Maior). Assim, embora generalize alguma da informação nas áreas mais populosas, evita a complexificação e simplifica a leitura, utilizando ainda a diferença de saturação ao aumentar a intensidade do vermelho nas superfícies dos restantes círculos que se sobrepõem (figuras 5 e 6 ).

Naturalmente, a conjugação de dois documentos com cariz territorial com datas díspares (Censos de 1920 e a Carta Corographica do Reino levantada durante toda a segunda metade do século XIX) colocaram problemas de adequação, nomeadamente, as mudanças de nomes de freguesias ou a inexistência, no mapa, de freguesias entretanto criadas, em ambos os casos referenciadas no Censo e, inversamente, as freguesias mencionadas no mapa mas sem valores referidos nos Censos. Nas primeiras situações, foram corrigidos ou acrescentados os topónimos, enquanto na segunda, frequente no Alentejo onde várias freguesias se encontravam anexadas a outras nos Censos de 1911 a 1930 (para o caso do distrito de Évora, ver X Recenseamento geral da população, 1960, Tomo I, Vol. I, pp. 139-143), o autor representou o círculo correspondente ao total populacional junto ao topónimo referido no Censo de 1920 e desenhou setas saindo dos topónimos correspondentes às freguesias anexadas e convergindo no círculo da freguesia anexadora (veja-se o exemplo do Redondo - figura 7).

Embora não apresente uma legenda explícita, porque foi registado junto a cada círculo/topónimo o valor de população correspondente, é possível, com o cálculo de algumas raízes quadradas e a construção de um ábaco (figura 8), verificar que não foi utilizada a proporcionalidade dos comprimentos dos raios, ou dos diâmetros, como era normal na cartografia temática anterior (Suzanne DAVEAU, 1995), assentando antes na proporcionalidade da superfície dos círculos como é geométrica e tecnicamente mais adequado. Curiosamente, este sinal de modernidade é apenas mais um contributo para a valorização da Carta da População de Portugal, a qual, apesar de surgir em contexto empresarial privado, deve ser integrada nas representações de implantação pontual de valores absolutos da população, de responsabilidade de geógrafos académicos, que começaram a surgir nesta época, entre os anos 20 e 50 do século XX (Maria Helena DIAS, 1991, p. 11).

$\mathrm{Na}$ verdade, Maria Helena Dias refere-se às "representações pontuais", ou seja, tendo como base de representação a técnica de mapas de pontos. Contudo, quer em alguns dos exemplos que refere, quer na proposta de representação que propõe para a representação da "distribuição da população" em 1981, considera a técnica do mapa de pontos e a dos círculos proporcionais. Os exemplos em relação a Portugal Continental são: o mapa de H. Lautensach, de 1932, na escala 1:1.500.000, relativo à população residente de 1920 e utilizando os círculos proporcionais para os valores superiores a 9750 habitantes (Maria Helena DIAS, 1991, pp. 13-14); o mapa sob a responsabilidade de Orlando Ribeiro, de 1955, na escala de 1:500.000, sobre a população residente de 1940, que usa a proporcionalidade a partir de 950 habitantes (Maria Helena DIAS, 1991, pp. 22-21); o mapa da Distribuição da População, 1981, concebido por Maria Helena Dias, na escala de 1:1.000.000, onde, como nos anteriores, 0 valor de cada ponto corresponde a 500 habitantes, mas que integra os círculos proporcionais a partir dos 500 habitantes, quer no mapa de Portugal relativo à população residente de 1981, quer nos seus "ensaios" com a população de 1911 e de 1940 (Maria Helena DIAS, 1991, pp. 52-55).

Naturalmente, outros exemplos de representação de valores absolutos da população são referidos (Maria Helena DIAS, 1991, p. 13), como o de Fernandes Martins em relação à Bacia do Mondego, de 1940, e os de Amorim Girão sobre a Bacia do Vouga, de 1922, sobre a Serra de Montemuro, de 1940, e, principalmente, os do Atlas de Portugal, de 1941 e 1958 ( $2^{\mathrm{a}}$ edição). No entanto, embora em qualquer destes casos sejam utilizados pontos e diferentes tamanhos de círculos, por vezes conjugados com diferentes tamanhos de quadrados, mas sem relação de proporcionalidade, importa lembrar que pontos e círculos têm afinidades e "não são sistemas de representação totalmente distintos: os primeiros, sempre iguais, ocorrem isolados ou agrupam-se (...) enquanto os segundos diferem no tamanho, mas sempre numa relação directa entre a figuração gráfica e os dados numéricos e entre 0 número e o tamanho" (Maria Helena DIAS, 1991, p. 146), seja ou não uma relação de proporcionalidade.

Assim, a Carta da População de Portugal, de 1929, deve ser integrada, por direito próprio, neste distinto conjunto das representações pontuais de valores absolutos da população, "destronando" o mapa de H. Lautensach (1932) no título de "primeiro mapa", "reportando-nos ao conjunto do país" (Maria Helena DIAS, 1991, p. 11), visto que, embora construído sobre uma base cartográfica na escala de 1:100.000, as decisões sobre 0 tamanho e a proporcionalidade dos círculos, bem como sobre todas as opções técnicas, foram incontestavelmente ponderadas tendo em conta a totalidade das 37 folhas da Carta Corographica do Reino e portanto do conjunto do país, desde 
os 486.372 habitantes de Lisboa aos 124 de Agra de S. João. Aliás, construindo-se a composição do respetivo puzzle e imprimindo-se o resultado à escala "clássica" dos mapas de Portugal Continental, normalizada a partir da Carta Geral do Reino de 1865, encontra-se um resultado que permite uma leitura e análise adequada e pertinente (figura 9).

De facto, independentemente da grande quantidade de informação da base cartográfica de cada folha da Carta Corographica do Reino, o salientar das redes hidrográfica e ferroviária e o relevo adquirido pelos círculos com a utilização da cor, tornam-na num documento bem sugestivo e legível, possibilitando a verificação da estruturação nacional e regional do povoamento em 1920 e mantendo a possibilidade de utilização individualizada de cada folha para abordagens mais localizadas.

Naturalmente, as possibilidades técnicas de então não permitiam as reduções e reproduções que hoje são possíveis. De qualquer forma, mesmo com as limitações técnicas coevas, a restrita divulgação deste documento, não permitiu que fosse inserido e considerado como contributo para os ensaios dos anos 20 e 40 (Maria Helena DIAS, 1991, p. 25), cujo processo se desenvolvia na academia, entre os geógrafos, como bem demonstra 0 "debate" entre Amorim Girão e Orlando Ribeiro em torno das questões relativas ao rigor das bases cartográficas, relativamente às freguesias, e às opções cartográficas para a representação da população (MARQUES, H.; FERNANDES, M. G., 2013).

De qualquer forma, a cartografia temática ia ganhando estatuto privilegiado, quer enquanto instrumento utilizado pelos académicos para a análise e o conhecimento, quer como apoio à compreensão e à ação por parte de quem intervinha no território, como aparenta ter sido o caso da Carta da População de Portugal da responsabilidade do Engenheiro Constantino de Figueiredo Cabral (1885-1959).

O Eng ${ }^{\circ}$ Constantino Cabral nasceu na cidade do Porto, onde se licenciou em Engenharia civil e de Minas na Academia Politécnica, teve um percurso profissional sempre ligado aos transportes ferroviários. Entre 1912 e 1920 pertenceu aos quadros da CP, onde iniciou a carreira profissional, tendo ingressado, em 1920, na Companhia dos Caminhos-de-Ferro do Vale do Vouga, onde permanece como Engenheiro Chefe de exploração até 1926. Ruma então a Lisboa onde desempenha o cargo de Engenheiro-Diretor da mesma companhia junto da administração, até 31 de Dezembro de 1946, regressando, em 1947, à CP, quando esta absorveu a Companhia dos Caminhosde-Ferro do Vale do Vouga.

Entretanto, assessorou o Ministro Duarte Pacheco na conceção da moldura legislativa reguladora dos sistemas de transporte, foi delegado das companhias de via estreita no Conselho Superior de Viação e foi Presidente da Comissão Reguladora do Comércio dos Metais no início da segunda guerra mundial. No que aqui interessa, sublinhe-se que o facto de ter sido, a partir de 1926, assessor principal da administração dos Caminhos-de-Ferro do Vale do Vouga, ao que acresce ser esta Companhia a detentora do alvará dos transportes rodoviários complementares da estrutura ferroviária, contribuirá para explicar a elaboração dos mapas aqui tratados, nos quais se relevam as vias ferroviárias e se pode observar a distribuição da população, segundo o Censo de 1920, importante elemento para previsões de potenciais utilizadores de serviços de transporte. 


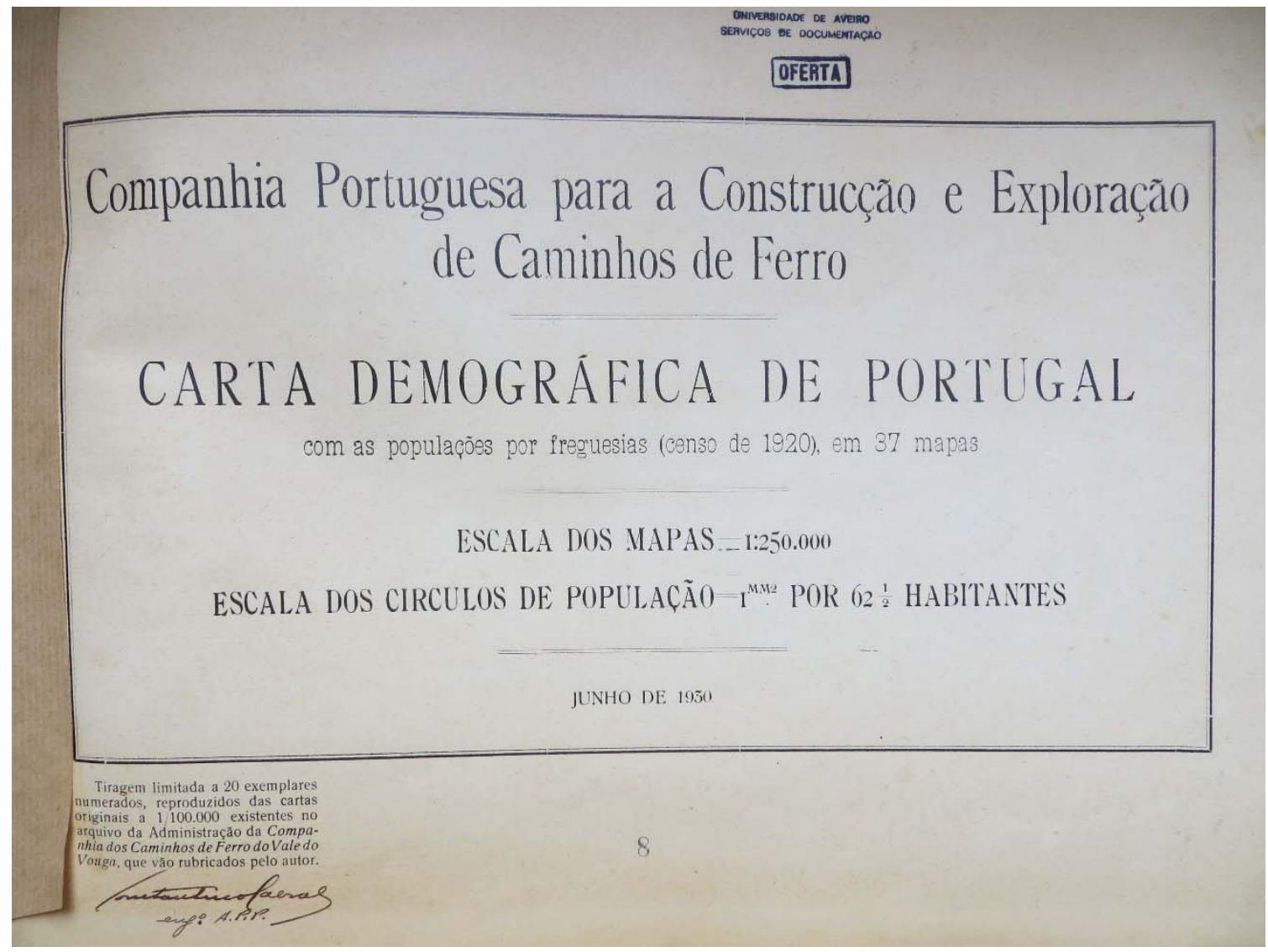

Figura 1 - Carta Demográfica de Portugal (1930), folha de rosto

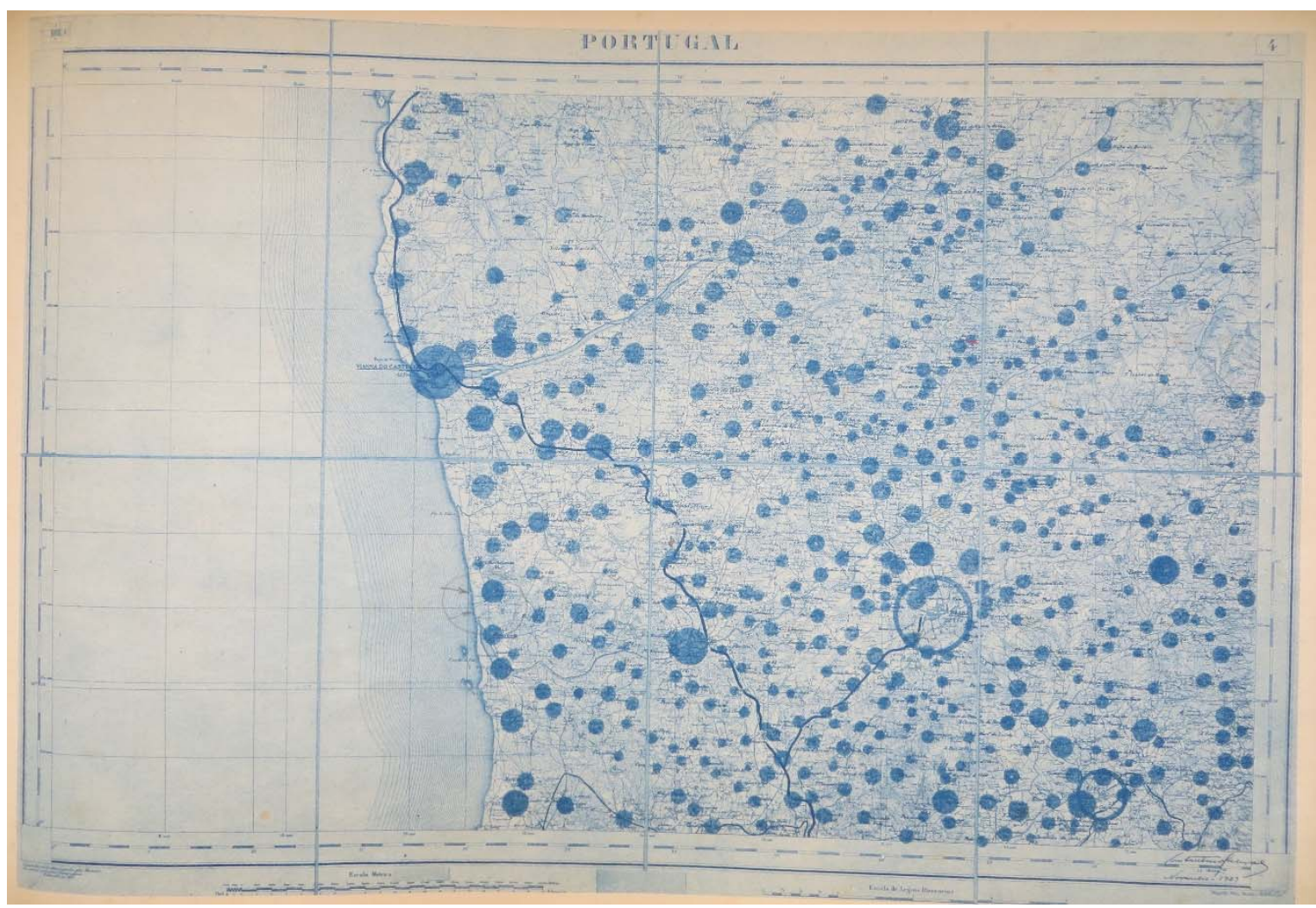

Figura 2 - Carta Demográfica de Portugal (1930), folha n 40 

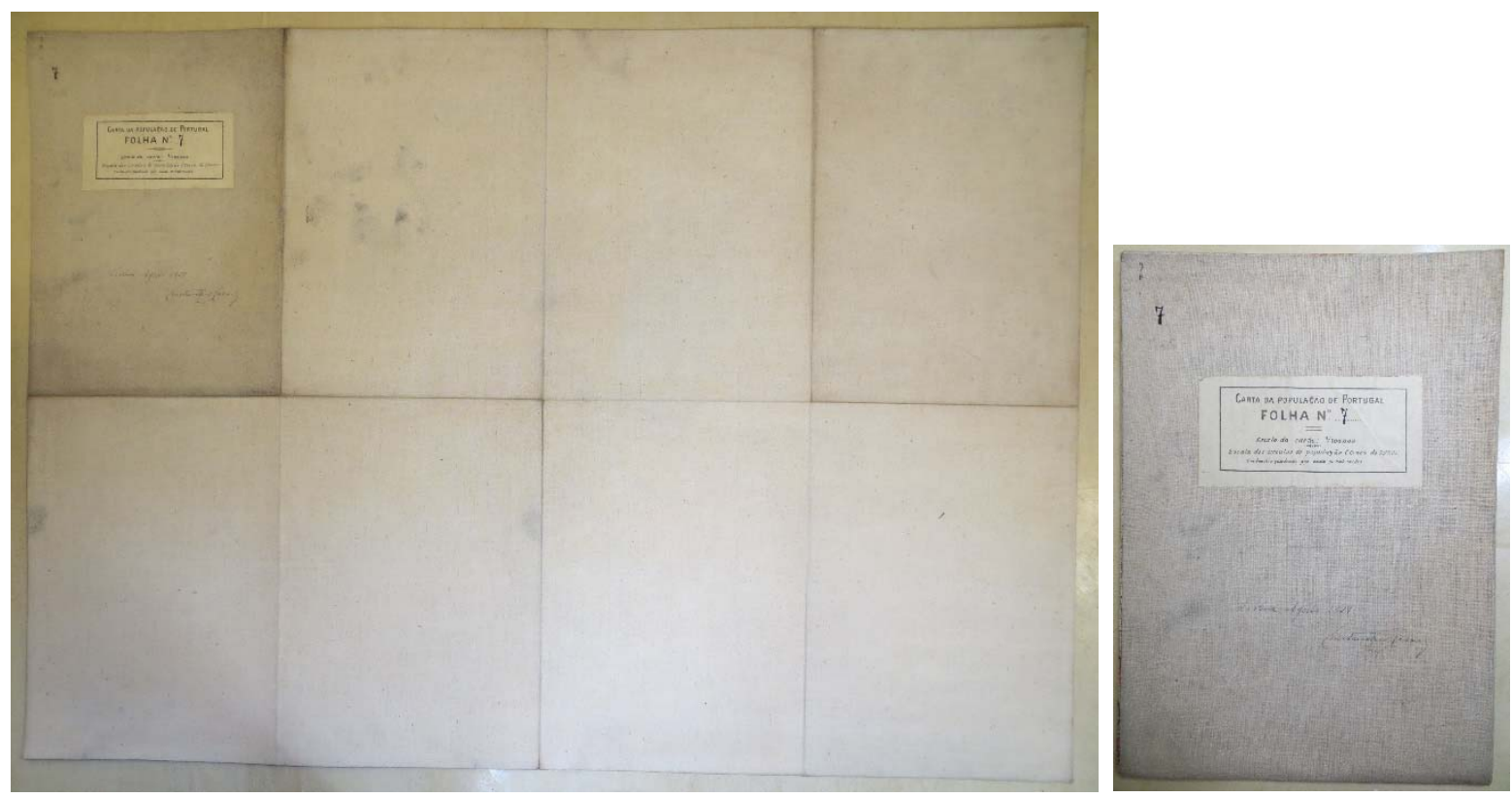

Figura 3 - Exemplo de verso de folha da Carta da População de Portugal (1929), folha n ${ }^{0} 7$

\begin{tabular}{|c|c|c|c|}
\hline $\begin{array}{c}1 \\
\text { Valença } \\
\text { dez/29 } \\
\end{array}$ & $\begin{array}{c}2 \\
\text { Tourém } \\
\text { dez/29 } \\
\end{array}$ & $\begin{array}{c}3 \\
\begin{array}{c}\text { Rio de Onôr } \\
\text { dez/29 }\end{array} \\
\end{array}$ & \\
\hline $\begin{array}{c}4 \\
\text { Viana do Cast. } \\
\text { dez/29 }\end{array}$ & $\begin{array}{c}5 \\
\text { Chaves } \\
\text { dez/29 }\end{array}$ & $\begin{array}{c}6 \\
\text { Bragança } \\
\text { dez/29 }\end{array}$ & \\
\hline $\begin{array}{c}7 \\
\text { Porto } \\
\text { ago/29 }\end{array}$ & $\begin{array}{c}8 \\
\text { Lamego } \\
\text { ago/29 }\end{array}$ & $\begin{array}{c}\mathbf{9} \\
\text { T de Moncorvo } \\
\text { dez/29 }\end{array}$ & \\
\hline $\begin{array}{c}10 \\
\text { Aveiro } \\
\text { ago/29 }\end{array}$ & $\begin{array}{c}11 \\
\text { Viseu } \\
\text { ago/29 }\end{array}$ & $\begin{array}{c}12 \\
\text { Almeida } \\
\text { dez/29 }\end{array}$ & \\
\hline $\begin{array}{c}13 \\
\text { Coimbra } \\
\text { ago/29 }\end{array}$ & $\begin{array}{c}14 \\
\text { S. da Estrela } \\
\text { ago/29 }\end{array}$ & $\begin{array}{c}15 \\
\text { Penamacor } \\
\text { dez/29 }\end{array}$ & \\
\hline $\begin{array}{c}16 \\
\text { Pombal } \\
\text { ago/29 }\end{array}$ & $\begin{array}{c}17 \\
\text { Cast. Branco } \\
\text { ago/29 }\end{array}$ & $\begin{array}{c}18 \\
\text { Idanha a Nova } \\
\text { dez/29 }\end{array}$ & \\
\hline $\begin{array}{c}19 \\
\text { Peniche } \\
\text { dez/29 }\end{array}$ & $\begin{array}{c}20 \\
\text { Tores Novas } \\
\text { ago/29 }\end{array}$ & $\begin{array}{c}21 \\
\text { Portalegre } \\
\text { ago/29 }\end{array}$ & \begin{tabular}{|c|}
22 \\
N.S. Esperança \\
dez/29
\end{tabular} \\
\hline $\begin{array}{c}23 \\
\text { Liaboa W } \\
\text { dez/29 }\end{array}$ & $\begin{array}{c}24 \\
\text { Lisboa E } \\
\text { dez/29 }\end{array}$ & $\begin{array}{c}25 \\
\text { Estremoz } \\
\text { dez/29 }\end{array}$ & $\begin{array}{c}\mathbf{2 6} \\
\text { Elvas } \\
\text { dez/29 }\end{array}$ \\
\hline \multirow[t]{4}{*}{$\begin{array}{c}27 \\
\text { Lisboa S } \\
\text { dez/29 }\end{array}$} & $\begin{array}{c}28 \\
\text { Barreiro } \\
\text { dez/29 }\end{array}$ & $\begin{array}{l}29 \\
\text { Évora } \\
\text { dez/29 }\end{array}$ & $\begin{array}{c}30 \\
\text { Granja } \\
\text { dez/29 }\end{array}$ \\
\hline & $\begin{array}{c}31 \\
\text { Sines } \\
\text { dez/29 }\end{array}$ & $\begin{array}{c}32 \\
\text { Beja } \\
\text { dez/29 }\end{array}$ & $\begin{array}{c}33 \\
\text { Amarleja } \\
\text { dez/29 }\end{array}$ \\
\hline & $\begin{array}{c}34 \\
\text { Odemira } \\
\text { dez/29 }\end{array}$ & $\begin{array}{c}35 \\
\text { Mértola } \\
\text { dez/29 }\end{array}$ & \\
\hline & $\begin{array}{c}36 \\
\text { Lagos } \\
\text { dez/29 }\end{array}$ & $\begin{array}{c}37 \\
\text { Faro } \\
\text { dez/29 }\end{array}$ & \\
\hline
\end{tabular}

Figura 4 - Esquema de junção com indicação de datas de inserção da informação temática 


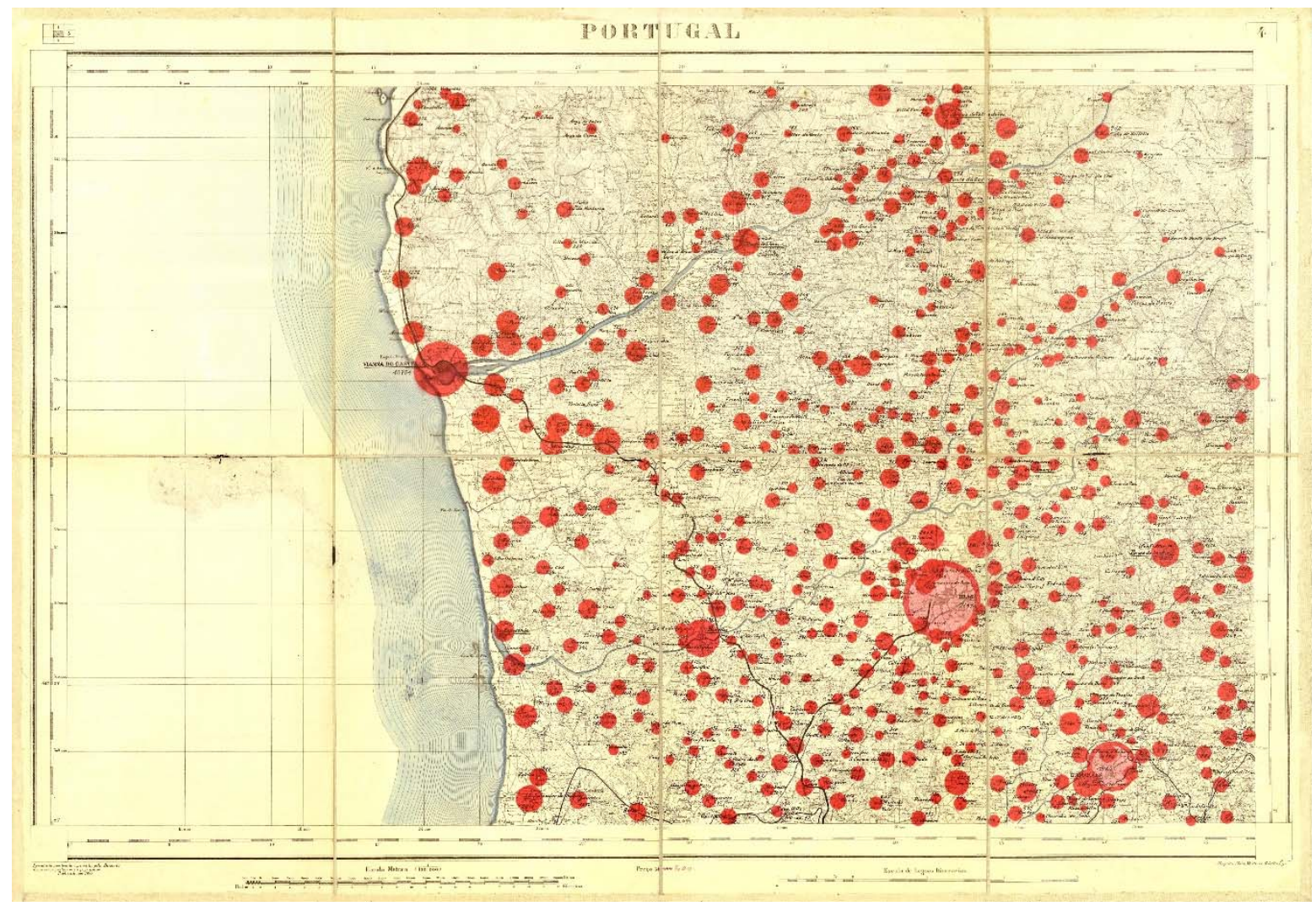

Figura 5 - Exemplo de folha da Carta da População de Portugal (1929), folha no 4

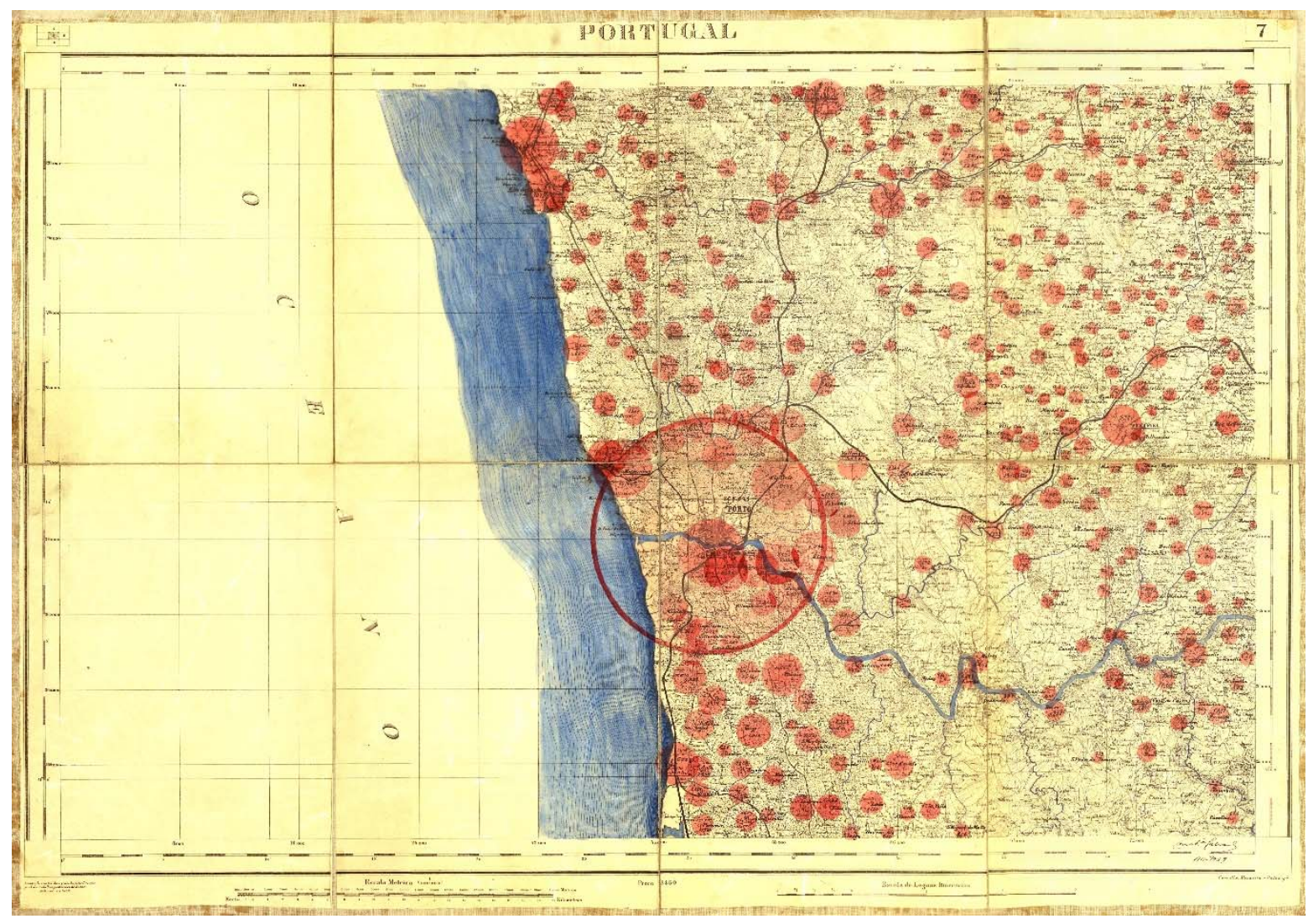

Figura 6 - Exemplo de folha da Carta da População de Portugal (1929), folha n 7 


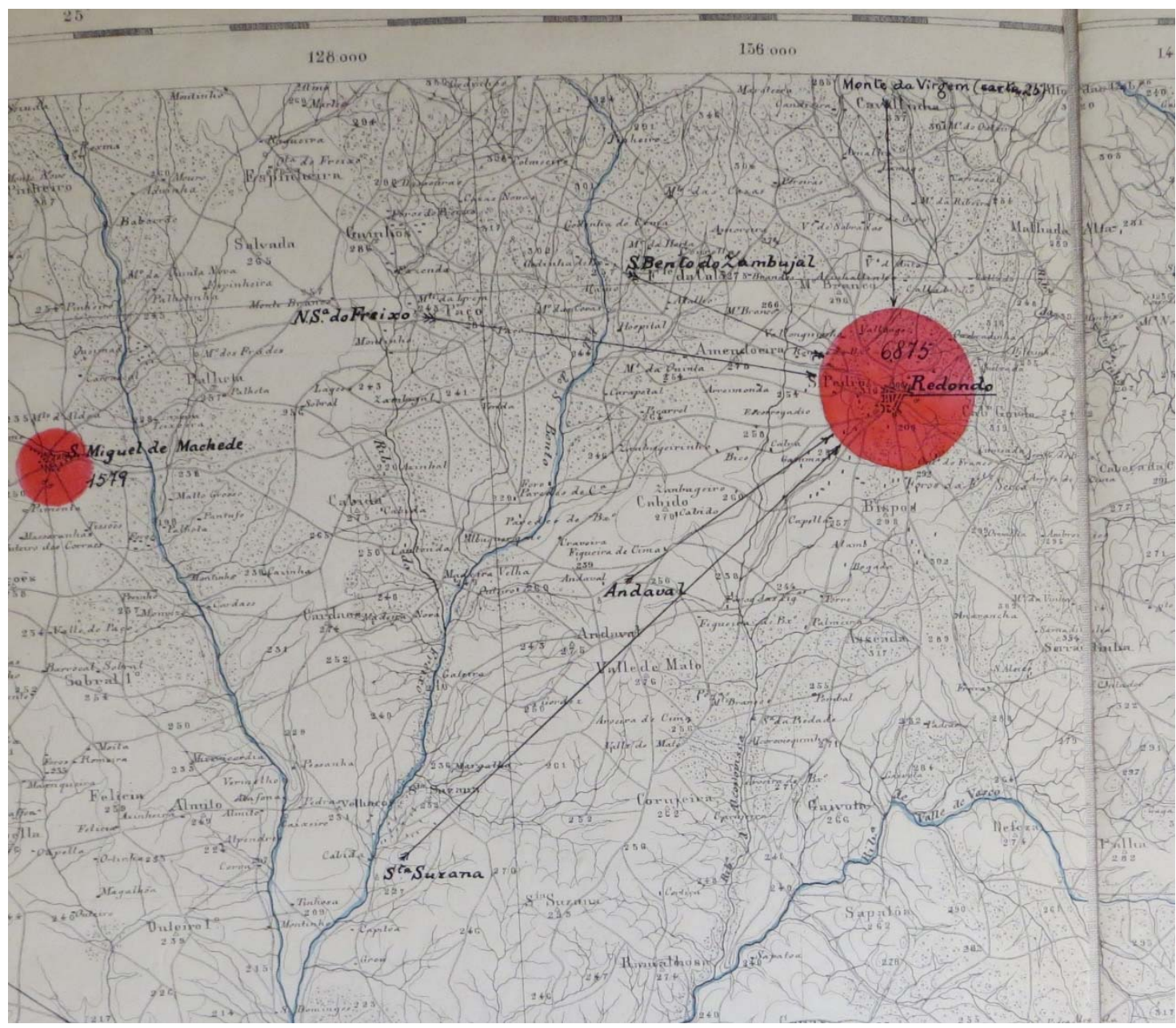

Figura 7 - Exemplo de técnica de indicação de freguesias anexadas

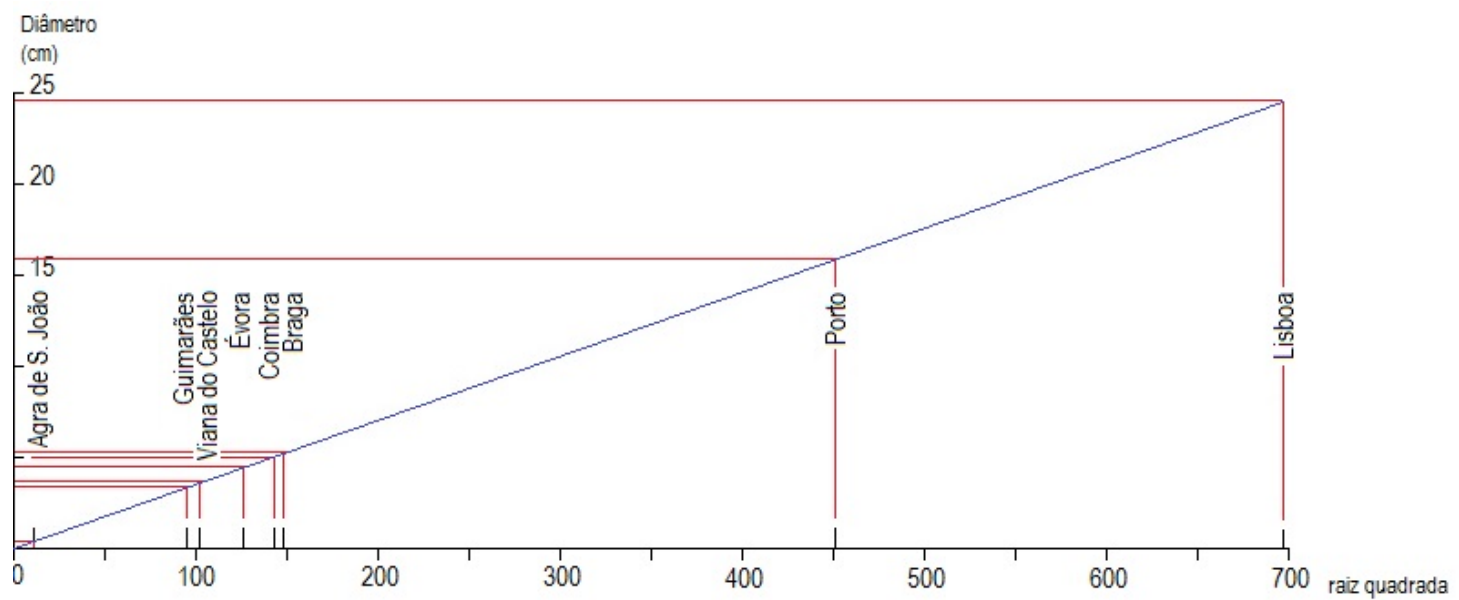

Ábaco com as raízes quadradas dos valores da população de 1920 e os diâmetros dos círculos do mapa de 1929

Figura 8 - Ábaco demonstrativo da proporcionalidade da superfície dos círculos da Carta da População de Portugal (1929) 


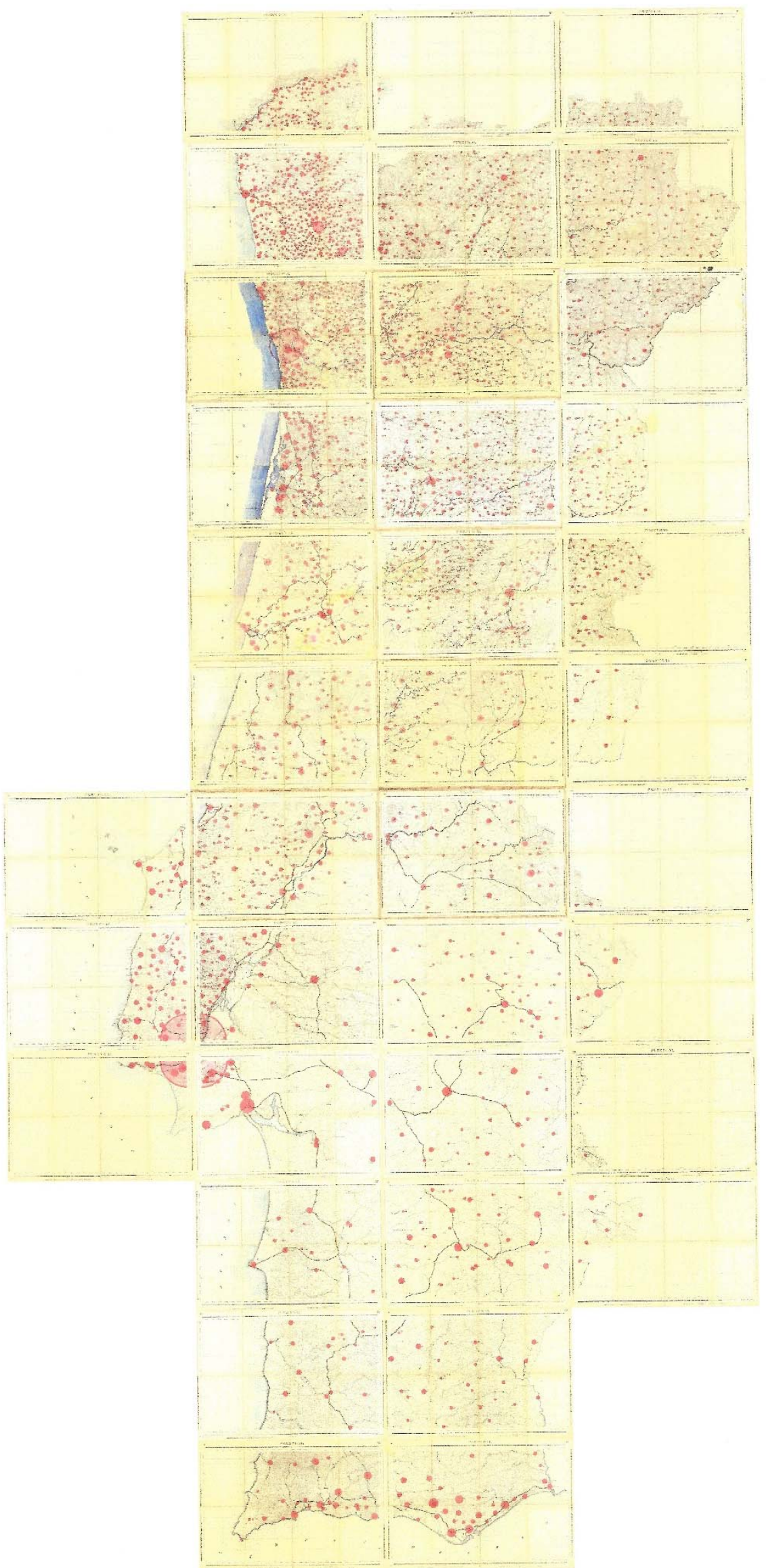

Figura 9 - Mapa de junção das folhas da Carta da População de Portugal (1929) 


\section{Referências bibliográficas}

ANUÁRIO do Instituto Politécnico do Porto do ano letivo 1902 /1903, Imprensa da Universidade, Coimbra, 1903.

DAVEAU, Suzanne (1995), "A Cartografia portuguesa moderna: os mapas temáticos", in Maria Helena DIAS, coord., Os Mapas em Portugal, da tradição aos novos rumos da cartografia. Lisboa, Ed. Cosmos, pp. 161-181.

DIAS, Maria Helena (1991), Contributos para o Atlas de Portugal: O Mapa da Distribuição da População Portuguesa em 1981. Lisboa, Centro de Estudos Geográficos, INIC, Linha de Acção de Geografia Regional e Histórica, Relatório no 10.

DIAS, Maria Helena (1995, coord.), Os Mapas em Portugal, da tradição aos novos rumos da cartografia. Lisboa, Ed. Cosmos.

DIRECÇÃO Geral de Estatística (1923), Censo da População de Portugal, 1920. Lisboa, Imprensa Nacional.

INSTITUTO Nacional de Estatística (1961), X Recenseamento geral da população, 1960. Lisboa, Imprensa Nacional, Tomo I, Vol. I.

MARQUES, H.; FERNANDES, M. G. (2013), "Dois momentos de consolidação da Geografia em Portugal e a concepção e representação cartográfica da 'Montanha'", V Simposio Luso-Brasileiro de Cartografia Historica, Petrópolis, Brasil.

GAZETA dos Caminhos de Ferro (1940 e 1946), nº 1271, pp. 785 a 788; n 1394, pp. 125 e 126.

GAZETA dos Caminhos de Ferro (1958), "Uma entrevista com o Sr. Eng ${ }^{\circ}$ Constantino de Figueiredo Cabral, antigo director de Exploração do caminho de ferro do Vale do Vouga", Cinquentenário do Caminho de Ferro do Vale do Vouga, Gazeta dos Caminhos de Ferro, no 1704, 16 de Dezembro de 1958, pp. 529-531.

GAZETA dos Caminhos de Ferro (1959), "Nota necrológica", Gazeta dos Caminhos de Ferro, nº 1715, 1959, p. 226. 